\title{
Catálogo Sociais - Relação de Publicações Acadêmicas Brasileiras de Ciências Sociais
}

\author{
Leandro Blanque Becceneri ${ }^{1}$
}

\section{Resumo}

A elaboração deste material tem como objetivo criar um catálogo de periódicos e publicações acadêmicas da área de Ciências Sociais que possa servir de guia a alunos e docentes na publicação de contribuições científicas para a área. Dessa forma, visa estimular e aproximar graduandos, pósgraduandos e demais interessados, do cotidiano da produção e publicação de trabalhos científicos nas três grandes áreas que compõem as Ciências Sociais. Esse trabalho se justifica a partir da constatação da não existência de um catálogo ou uma base sistematizada onde possam ser encontradas publicações da área, com informações sobre estratificação atribuídas pela CAPES, instituição, periodicidade e localização dessas publicações. Essa iniciativa teve início inspirada pelo trabalho de Carvalho e Di Maio (2011) que elaborou uma lista de páginas na web que disponibilizam dados e informações geoespaciais gratuitamente. O presente trabalho ocorre durante a realização do mestrado em Ciências Sociais vinculado ao Programa de Pósgraduação em Ciências Sociais (PPGCS) da Universidade Federal de São Paulo (UNIFESP).

\footnotetext{
1 E-mail: leandrobecc@hotmail.com - Telefone: (12) 9.9792.9995, Mestrando do Programa de Pós-graduação em Ciências Sociais da Universidade Federal de São Paulo (UNIFESP). Orientador: Prof. Dr. Humberto Prates da Fonseca Alves.
} 


\section{O conceito Qualis e suas categorias}

Para prosseguir com o trabalho de catalogação das revistas acadêmicas da área de Ciência Sociais foi feita antes uma pesquisa sobre o conceito de Qualis e sua funcionalidade e significado. A partir daí desenvolveu-se uma pesquisa sobre tal conceito e extraídos alguns trechos do portal WebQualis, da CAPES.

Assim sendo, é importante definir o que é Qualis. Segundo o portal WebQualis, da CAPES (2014), Qualis é o conjunto de procedimentos utilizados pela própria CAPES para estratificação através da avaliação da qualidade da produção científica dos programas de pós-graduação e dos centros de pesquisa brasileiros. Esse sistema foi criado para atender necessidades específicas do sistema de avaliação sendo baseado nas informações fornecidas por meio da utilização de um software chamado Coleta de Dados. Como resultado, disponibiliza uma lista com a classificação dos periódicos utilizados pelos programas de pós-graduação e instituições de pesquisa para a divulgação da sua produção.

A estratificação da produção é realizada de forma indireta, sendo que o Qualis determina a qualidade dos artigos e de outros tipos de produção a partir da análise da qualidade dos veículos de divulgação, ou seja, dos periódicos científicos. Assim, essa avaliação não é feita diretamente pela análise do artigo, mas sim através de onde este foi publicado. Utiliza-se então uma lista que categoriza essa qualidade da produção, que possui oito estratos, ordenados de forma decrescente, sendo eles: A1, A2, B1, B2, B3, B4, B5 e C (CAPES, 2014). Os quatro primeiros estratos ficaram assim classificados:

A1- Fator de Impacto igual ou superior a 3,800

A2- Fator de Impacto entre 3,799 e 2,500 
B1- Fator de Impacto entre 2,499 e 1,300

B2- Fator de Impacto entre 1,299 e 0,001

Para ser incluído nos quatro estratos superiores, o periódico deve ter fator de impacto medido pelo Institute for Scientific Information (ISI).

Segundo Bastos (2010) essa estratificação segue alguns princípios:

- A posição do periódico na escala depende do seu fator de impacto;

- O número de periódicos A1, que é o estrato superior da escala, deve ser inferior ao de A2;

- A soma de $\mathrm{A} 1+\mathrm{A} 2$ deve corresponder a, no máximo, $26 \%$ dos periódicos em que a área publicou artigos no triênio anterior; A1 + A2 + B1 não pode ultrapassar 50\% de todos os periódicos do triênio anterior.

No caso dos demais periódicos, B3, B4 e B5 (que não possuem fator de impacto) o indicador de classificação é a base de dados em que os mesmos estão indexados (idem, 2010). Conforme demonstrado abaixo:

- Indexação de periódicos em bases internacionais, de amplo acesso e veiculação, confere classificação mais elevada. Exemplo: os periódicos indexados no Medline/PubMed são classificados como B3.

- Versões eletrônicas de periódicos indexados no ISI, mas que ainda não possuam sua própria indexação são classificados como B3.

- Periódicos indexados no SciElo são classificados como B4.

- Periódicos indexados no LILACS, LATINDEX ou semelhantes são classificados como B5. 
- Os periódicos irrelevantes para a área são classificados no estrato C o que significa que não receberam pontuação.

Por fim, é importante destacar que a classificação dos periódicos é atualizada anualmente. Também cabe ressaltar que alguns periódicos não apresentam apenas classificação em uma área, sendo que podem ser classificados em duas ou mais áreas distintas (como Sociologia, Ciência Política e Administração) podendo receber diferentes avaliações do critério Qualis.

\section{Publicações}

Os periódicos a seguir encontram-se organizados em ordem alfabética, havendo separação apenas dos exclusivos para graduandos e das publicações estrangeiras. As informações das revistas foram obtidas através da internet, em páginas oficiais, redes sociais e também nas chamadas para contribuições que são divulgadas nos programas de pós-graduação das universidades. Com relação à estratificação Qualis, foi utilizado o próprio website da CAPES ${ }^{2}$ consultando o número do ISSN dos periódicos, com preferência para os de publicação eletrônica.

\section{Agenda política}

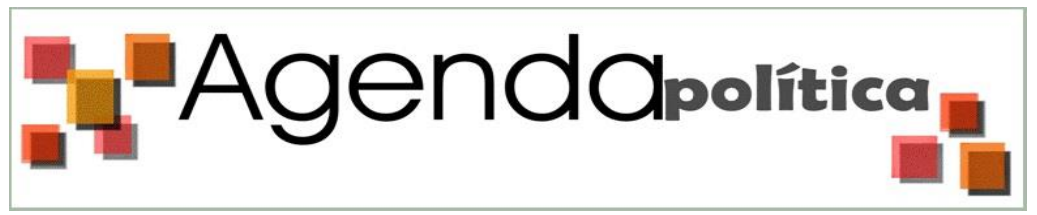

A Revista Agenda Política (ISSN: 2318-8499) é organizada pelos alunos de Pós-Graduação em Ciência Política da Universidade Federal de São Carlos

\footnotetext{
${ }^{2}$ http://qualis.capes.gov.br/webqualis/principal.seam
} 
(UFSCar). Sua periodicidade é em regime semestral de publicação. Ainda não possui uma classificação pelo conceito Qualis. As submissões de trabalhos são feitas através do OJS, necessitando cadastramento.

Website: http://www.agendapolitica.ufscar.br/index.php/agendapolitica/index

\section{Agenda Social}

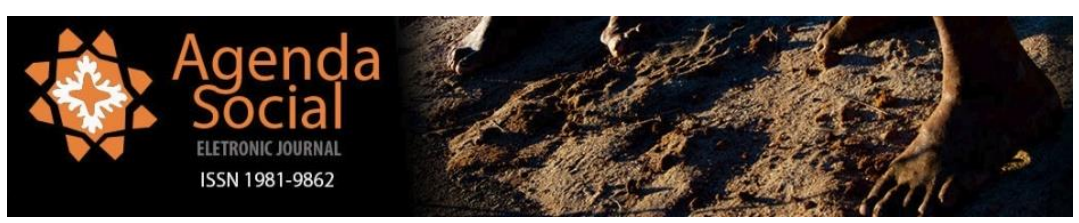

A Revista Agenda Social (ISSN: 1981-9862) é uma publicação da Universidade Estadual do Norte Fluminense (UENF). Sua periodicidade é em regime semestral de publicação. Possui classificação $\mathbf{B 5}$ pelo conceito Qualis. As submissões de trabalhos são feitas através do Open Journal Systems (OJS), necessitando cadastramento.

Website: http://www.revistaagendasocial.com.br/index.php/agendasocial/index

\section{Alabastro}

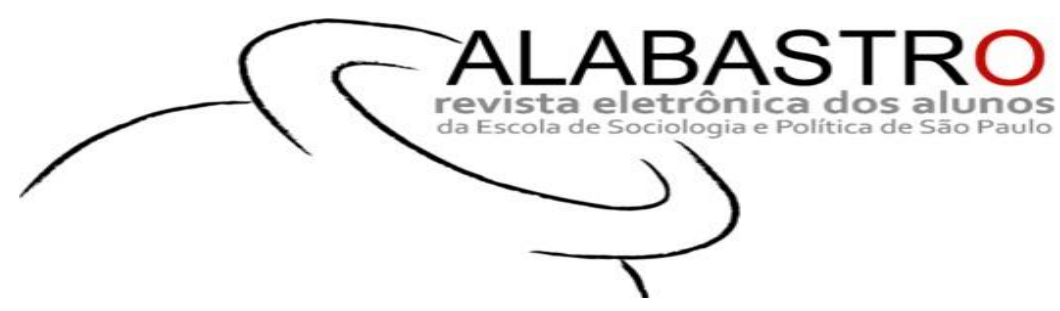

A Revista Alabastro (ISSN: 2318-3179) é uma publicação organizada por estudantes de graduação em Ciências Sociais da Escola de Sociologia e Política de São Paulo. Sua periodicidade é em regime semestral de publicação. Ainda não possui uma classificação pelo conceito Qualis. As submissões de trabalhos são feitas através do Open Journal Systems (OJS), necessitando cadastramento. 
Website: http://revistaalabastro.fespsp.org.br/index.php/alabastro

\section{Amazônica}

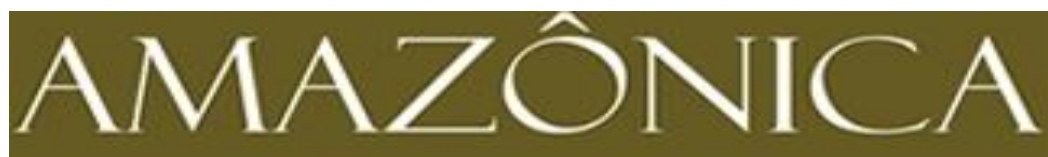

REVISIA DE ANIROROLOGIA

A Revista Amazônica (ISSN: 2176-0675) é uma é um periódico científico internacional. Sua periodicidade é em regime semestral de publicação. Possui classificação B2 para Antropologia e Sociologia, pelo conceito Qualis. As submissões de trabalhos são feitas através do Open Journal Systems (OJS), necessitando cadastramento.

Website: http://www.periodicos.ufpa.br/index.php/amazonica/index

\section{Ambivalências}

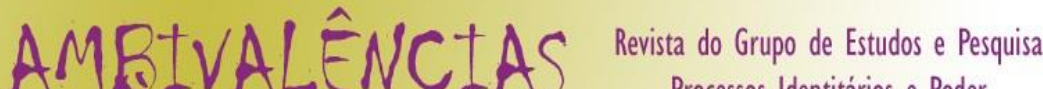 Processos Identitários e Poder}

A Revista Ambivalências (ISSN: 2318-3888) é uma publicação do Grupo de Pesquisa "Processos Identitários e Poder" (GEPPIP) que reúne alunos e professores da Universidade Federal de Sergipe (UFS). Ainda não possui uma classificação pelo conceito Qualis. As submissões de trabalhos são feitas através do Open Journal Systems (OJS), necessitando cadastramento.

Website: http://www.seer.ufs.br/index.php/Ambivalencias/index

\section{Anthropológicas}

ANTHROPOLÓGICAS 
A Revista Anthropológicas (ISSN: 1516-7372) é uma publicação do Programa de Pós-graduação em Antropologia (PPGA) da Universidade Federal de Pernambuco (UFPE). Possui classificação B1 para Antropologia, B2 para Sociologia e B4 para Ciência Política, pelo conceito Qualis. As submissões de trabalhos são feitas através do Open Journal Systems (OJS), necessitando cadastramento.

Website: http://www.revista.ufpe.br/revistaanthropologicas/index.php/revista/index

Palavras Chave: Periódicos, Ciências Sociais, Catálogo, Revistas

\section{Referências}

BASTOS, V. C. Classificação de periódicos no Qualis/CAPES. UFPA, Pará, 2010.

Disponível em

<www.biblioteca.ics.ufpa.br/arquivos/QUALIS-rev_26_11.pdf12305,d.aWw >.

CAPES, Coordenação de Aperfeiçoamento de Pessoal de Nível Superior. Portal WEBQUALIS. Brasília, 2014. Disponível em

$\langle$ http://qualis.capes.gov.br/webqualis/principal.seam〉.

CARVALHO, M. V. A.; DI MAIO, A. C. Proposta para a difusão de dados e informações geoespaciais disponíveis gratuitamente na Internet junto aos graduandos e professores da educação básica. In: SIMPÓSIO BRASILEIRO DE

SENSORIAMENTO REMOTO, 15. (SBSR), 2009, Curitiba. Anais... São José dos Campos: INPE, 2011. Disponível em:

<http://www.dsr.inpe.br/sbsr2011/files/p0612.pdf> 